\title{
Psychoacoustic evaluation of internal combustion engine noises
}

\author{
Sebastian Schneider ${ }^{1} \cdot$ Tommy Luft $^{1} \cdot$ Hermann Rottengruber $^{1}$
}

Received: 11 August 2021 / Accepted: 21 September 2021 / Published online: 13 October 2021

(c) The Author(s) 2021

\begin{abstract}
When buying a car, the acoustic impression of quality of a vehicle drive train is becoming more and more relevant. The perceived sound quality of the engine unit plays a key role here. Due to the nature of individual background noises, that sound quality is negatively influenced. These noise components, which are perceived as unpleasant, need to be further reduced in the course of vehicle development with the identification and evaluation of disruptive noise components in the overall engine noise being a prerequisite for effective acoustics optimization. In particular, the pulsed ticker noise is classified as particularly annoying in Otto DI engines, which is why this article aims to analyze and evaluate the ticking noise components from the overall noise. For this purpose, an empirical formula was developed which can classify the ticking noise components in terms of their intensity. This is purely perception-based and consists of the impulsiveness, the loudness and the sharpness of the overall engine noise. As with other psychoacoustic evaluation scales, the rating was made from 1 (very ticking) to 10 (not ticking). The ticker noise evaluation formula was then verified on the basis of hearing tests with the help of a jury of experts. According to this, it can be predicted precisely in which engine map areas the ticker noise undermines the pleasantness of the overall engine noise.
\end{abstract}

Keywords Psychoacoustics $\cdot$ Ticking noise $\cdot$ Noise assessment

\section{Introduction}

The requirements placed on modern combustion engines are becoming increasingly stringent due to stricter legislation and growing demands on the part of customers. In addition to limitations in terms of emissions and fuel consumption, the focus on the acoustics of an internal combustion engine comes more to the fore. The current trend is toward lighter, more efficient but also more complex assemblies, which can significantly influence the acoustic properties of a vehicle. High-pressure direct injection in particular has a considerable influence on the acoustic interference behavior of both diesel and gasoline engines. The overall noise of internal combustion engines is getting quieter despite the increase in performance and lightweight construction due to new technologies. As a result, background noises, which are perceptible as disturbing, increasingly come to the fore. Well-known disturbing noises include the so-called diesel knocking and the ticker noise. Diesel knocking results from self-ignition

Sebastian Schneider

sebastian.schneider@ovgu.de

1 Otto-Von-Guericke-University, Magdeburg, Deutschland and the resulting rapid and strong pressure increase in the cylinder. The ticker noise is caused by the high-pressure injection system and can therefore occur in modern diesel and gasoline engines. Noise evaluation models should help to quantitatively and qualitatively evaluate overall engine noises and individual noise components to make relative statements as to whether and how unpleasant the engine noise appears.

In the context of this contribution, an empirical formula is to be developed based on acoustic measurements and evaluations, which is to evaluate the intensity of the ticker noise for stationary operating points.

\section{State of the art}

The evaluation of the noise quality of entire vehicles and in particular of internal combustion engines is playing an increasingly important role in the development process. To continuously optimize the evaluation process, the noise sources of various interfering noises must be defined immediately. In addition, the evaluation models must be adapted 
to the current and future engines and their innovative technologies.

\subsection{Sound assessment methods}

For the assessment of the annoyance of internal combustion engine noises, on the one hand, expert opinions based on hearing tests and, on the other hand, empirically developed evaluation formulas can be used. The "AVL Annoyance Engine Index" is an established evaluation formula for the annoyance of engine noises. The airborne sound emitted by an internal combustion engine is recorded with an artificial head or a microphone and the psychoacoustic parameters, such as loudness, sharpness and impulsiveness. These calculated basic parameters are combined into a single-number evaluation index. The higher the index is rated, the more unpleasant the noise is perceived [1]. Another practicable evaluation index is the "Diesel Knocking Index" developed by Ford, which evaluates typical diesel knocking. The impulsiveness and the volume level are combined to form a single value [2].

\subsubsection{Subjective sound assessment methods}

To assess the noise quality in the development process of engines and vehicles, subjective assessments are traditionally carried out by expert and lay juries. These have the disadvantage that they are very time-consuming and colored by the subjective impression of the evaluating people. Furthermore, small changes in the tonal component cannot be reliably detected, since the human ear reaches its physical limits in certain frequency ranges and pitches [3].

\subsubsection{Objective sound assessment methods}

In addition to the subjective noise evaluation methods, objective acoustic evaluation models are constantly being developed. Methods based on acoustic analyzes and calculations can be used for objective grading. It is difficult to differentiate between several types of impulsive noises occurring at the same time. Typical pulse-like types of noise for an internal combustion engine are knocking, ticking and rattling. The reason for this is the cross-sensitivity due to the very similar characteristics of the individual noises. With the help of modern signal analysis methods and acoustic calculation algorithms, it is possible to separate the background noises and then evaluate the individual noises [3]. The greatest advantage of subjective noise evaluation by adding software is the shortening and simplification of the entire noise evaluation process in the development and analysis of the engine.

\subsection{Origin of the ticker noise}

The ticker noise of a direct-injection engine can result from various sources, including the high-pressure pump, the injector and the valve train. The noise mainly arises from the opening and closing of different valves, which results in a valve surge, which is perceived acoustically as a ticking.

Figure 1 shows in more detail the locations of the ticker noise origin in the solenoid valve injector. On the one hand, the ticker noise is caused by the bouncing of the armature and iron core, whereby the armature hits the magnetic core, and on the other hand, by the closing impact of the injector needle on the valve seat. Most of the radiated noise is due to the injector needle falling back into the valve seat. In the case of the piezo injectors, which work much faster, the noise characteristics are further increased, so that they have a higher overall noise emission than the more commercially available solenoid valve injectors. Furthermore, Fig. 2 shows the frequency-dependent distribution of the impulsive noises on the combustion engine.

It can clearly be seen that the valves are delimited in the frequency range from the injectors and the high-pressure pump, whereas the latter overlap extensively in the range of about 4-12 kHz. Overall, it should be noted in this regard that the injectors show the greatest potential for background noise and their acoustic investigation. Therefore, this takes up a large part of this evaluation. For this purpose, Fig. 3 shows an exemplary course of a control current of a solenoid valve injector with two pre-injections and one main injection.

In the case of multiple injections in rapid succession, the noise is usually composed of several individual impulses. This results in impulse excitation, which on the one hand is emitted directly from the injector as airborne noise and on the other, spreads to the engine structure via structure-borne noise transfer paths. The described impulse excitation is strongest in the case of a pre-injection, since the needle is only attracted by the armature and is no longer held. Furthermore, the sound is transmitted via the fuel and is emitted by the fuel lines. In general, it should be noted that higher injection pressures lead to increased noise excitation [6].

In modern injection systems, a so-called "braking current" is applied in some applications to reduce the ticker noise, see Fig. 4, which brakes the needle shortly before it hits the valve seat, thereby reducing the kinetic energy of the needle. This is known as soft-landing [7].

Furthermore, the use of magnetic actuators can lead to a reduction in the noise emission caused by injector ticking. The reason for that is, for example, faster-acting piezo actuators stimulate the structure of the cylinder head to vibrate more strongly. Another way of reducing ticker noise that has been established in practice is the use of engine covers (top covers), which tones down the ticker noise $[3,8]$. 
Fig. 1 Noise sources of a magnetic injector during opening and closing process [4]
Fig. 2 Frequency areas of impulsive noises [5]
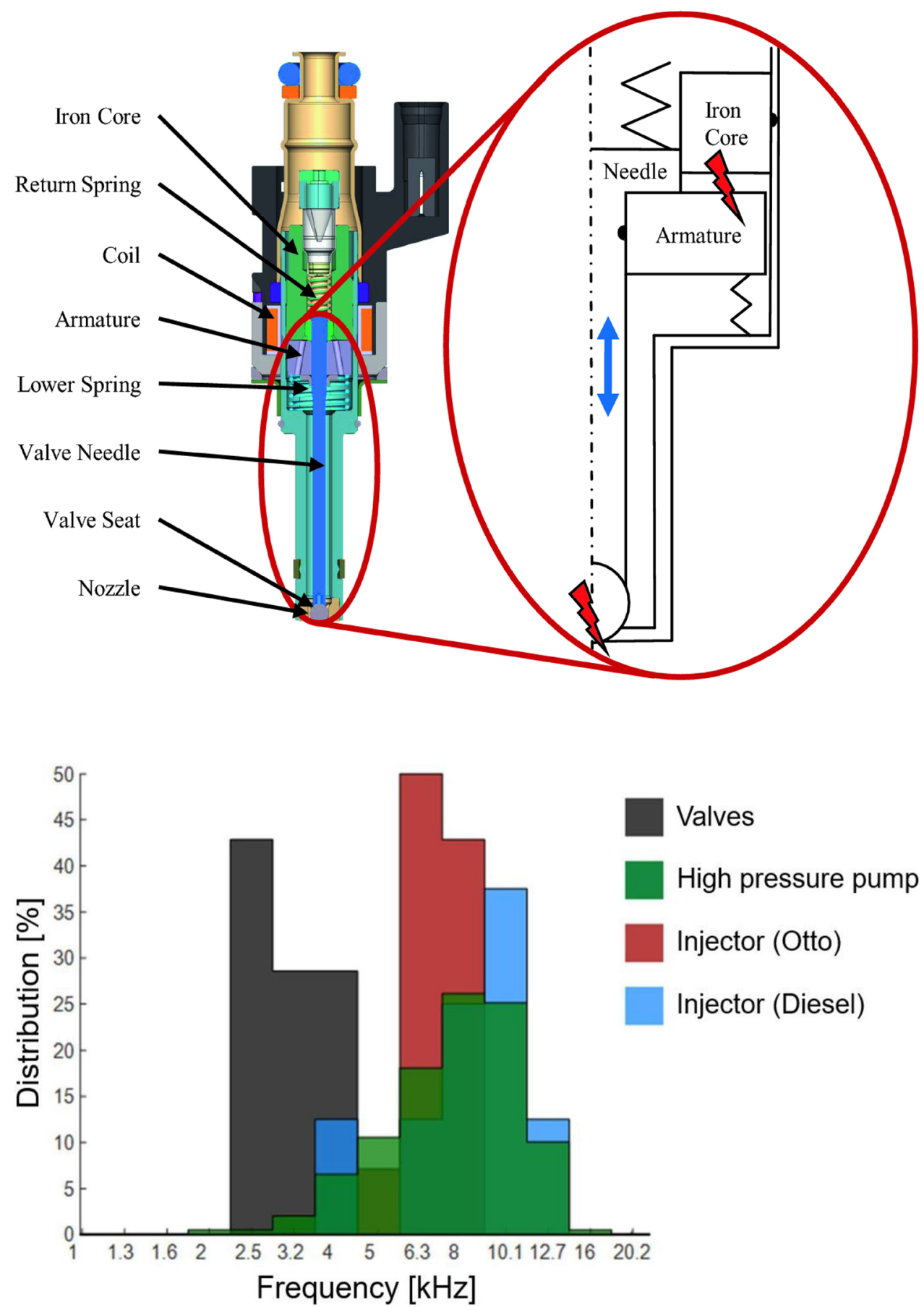

\section{Test bench setup and experimental procedure}

To carry out the measurement campaigns, the test item was operated on the acoustic test bench of the Institute for Mobile Systems at the Otto-von-Guericke-University of Magdeburg This acoustic test bench is located in a special engine test bench cabin. The test bench chamber is lined with sound-absorbing walls, whereby the centrally placed test object has sufficient distance to the respective wall surfaces to be able to carry out serious sound pressure measurements in the near or far field. Furthermore, an electric machine is used both as a starter and as a brake to generate the engine load. This is connected to the engine's crankshaft via a one and a half meter long, vibration-damping shaft and can provide permanent loads of up to $250 \mathrm{Nm}$ or short-term loads of up to $310 \mathrm{Nm}$. The e-machine is located in the adjacent room for acoustic reasons, which in turn explains the length of the test bench 
Fig. 3 Injector control current curve of an injection pattern with two pre-injections and one main injection

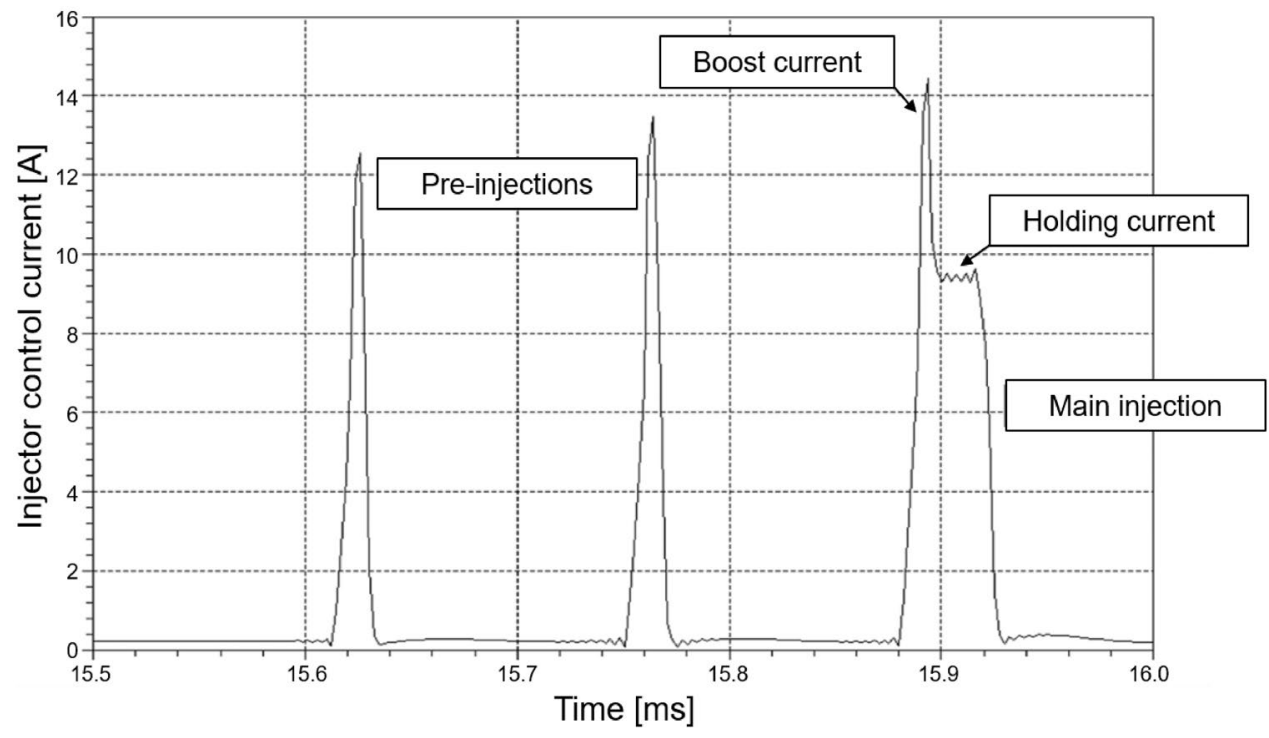

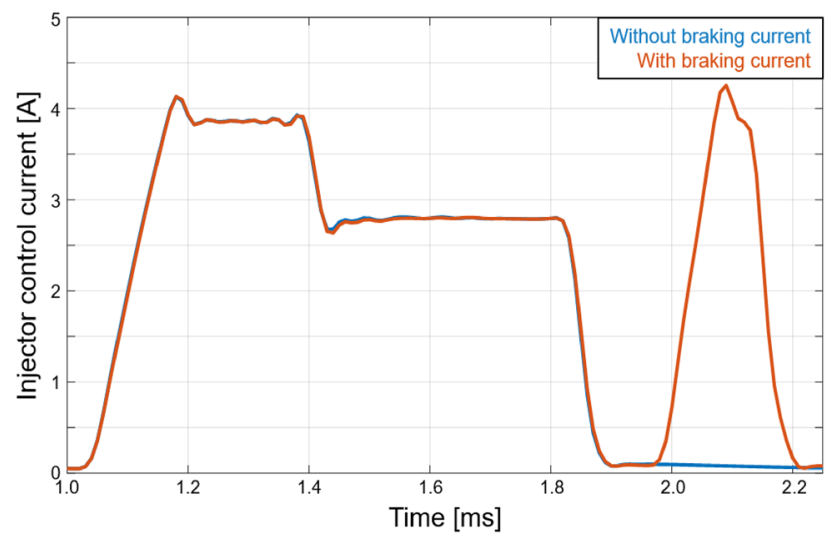

Fig. 4 Injector control current curve of an injection pattern with and without braking current (soft-landing of the injector needle) [7] shaft. The test engine is elastically mounted both on the front side and on the pressure side. The latter is a torque support.

\subsection{Test engine}

For the following investigations, a series 4-cylinder gasoline engine has been set up on the acoustic test bench, see Fig. 5 . The nominal parameters of the engine are shown in the following table (Table 1).

\subsection{Measurement technology and data evaluation}

A large number of acceleration sensors were used for the investigations on the gasoline engine. Mainly the injection
Fig. 5 Experimental setup of the gasoline engine on the acoustic test bench

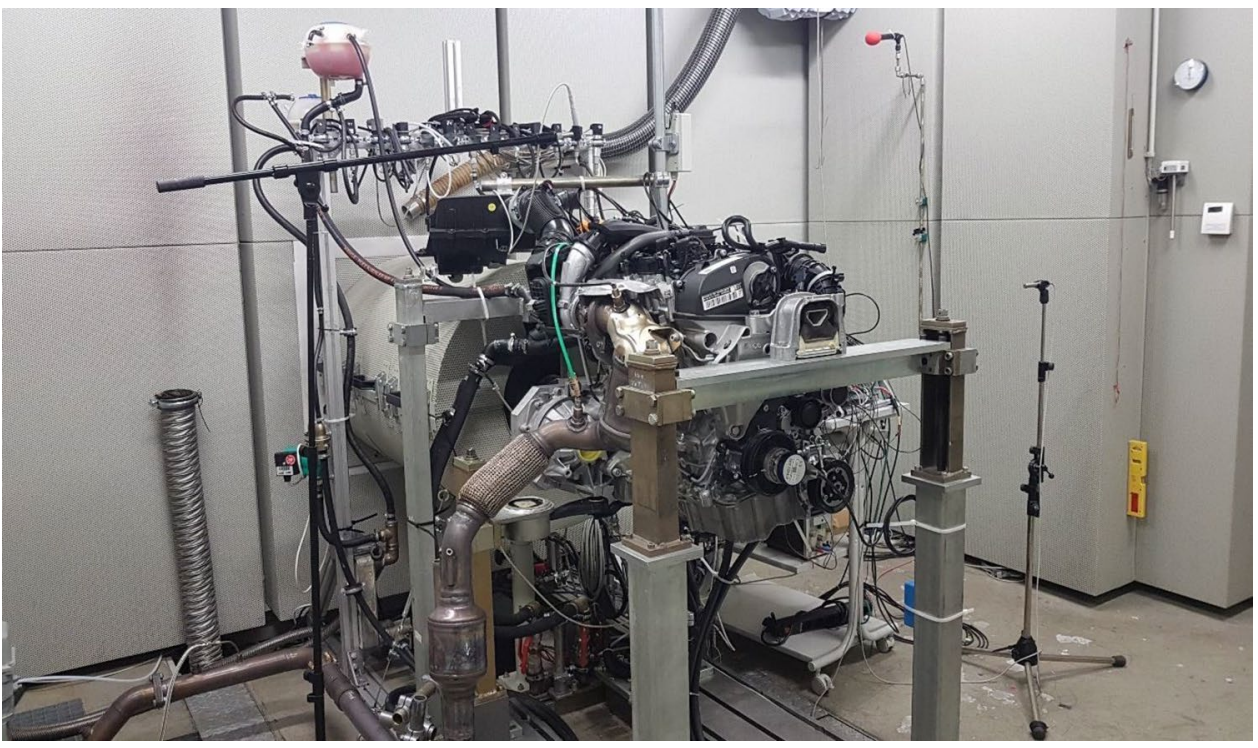


Table 1 Nominal parameters of the gasoline engine

\begin{tabular}{|c|c|}
\hline Type & 4-Cylinder Otto in-line engine \\
\hline Injection process & $\begin{array}{l}\text { Common-Rail-System with } \\
\text { solenoid injectors }\end{array}$ \\
\hline Displacement & $1498 \mathrm{~cm}^{3}$ \\
\hline Rated speed & $5000-6000 \mathrm{rpm}$ \\
\hline Power & $110 \mathrm{~kW}(150 \mathrm{PS})$ \\
\hline Torque & $250 \mathrm{Nm}(1500-3500 \mathrm{rpm})$ \\
\hline Compression ratio & $10.5: 1$ \\
\hline Firing order & $1-3-4-2$ \\
\hline
\end{tabular}

system noise should be analyzed, which is why all sensors are located in the area of the injection nozzles and the highpressure pump. Figure 6 shows the structure-borne noise measurement positions schematically (above) and in real terms (below).

For a sufficiently precise reproduction of the control behavior of each injector, the respective accelerometer had to be attached in the injection direction. What turned out to be easy to implement with the injectors on the diesel engine due to the longer component shape and the relatively simple type of installation, see [9], appeared to be more difficult with the much more compact injectors on the Otto engine. With the latter, there are no suitable injector clamping claws for absorbing structure-borne noise, which is why small crescent-shaped components were milled from aluminum, the inside diameter of which matches the outside diameter of the injectors, so that those components were glued to the side of the open surfaces of the injectors. In the end, the structure-borne noise sensors were attached to the bonded components in the direction of injection. This resulted in the best possible correlation between the injection process and structure-borne noise excitation according to the circumstances. Furthermore, all relevant engine sides in the far field were recorded by microphones. Likewise, current clamps were used to measure the injection control current and an incremental encoder to measure the engine speed and, like the acoustic input signals, were further processed with the help of an MKII system.

\subsection{Experimental procedure}

To analyze the acoustic behavior of the engine, various measurements were carried out on the engine test bench. At the beginning, a static map was run by varying the speed from 1000 to $4000 \mathrm{rpm}$ with a step size of $250 \mathrm{rpm}$ and increasing the load range from towing operation to a maximum of $250 \mathrm{Nm}$. Each individual operating point was set and measured for $5 \mathrm{~s}$. During the measurement process, attention should be paid to load fluctuations to make meaningful acoustic statements. Furthermore, dynamic load ramp-ups were carried out on the engine test bench at speeds of 1000-4000 rpm, each of which lasted $90 \mathrm{~s}$. With the help of this series of measurements and the evaluation software used, characteristic diagrams for the relevant acoustic parameters could be created.

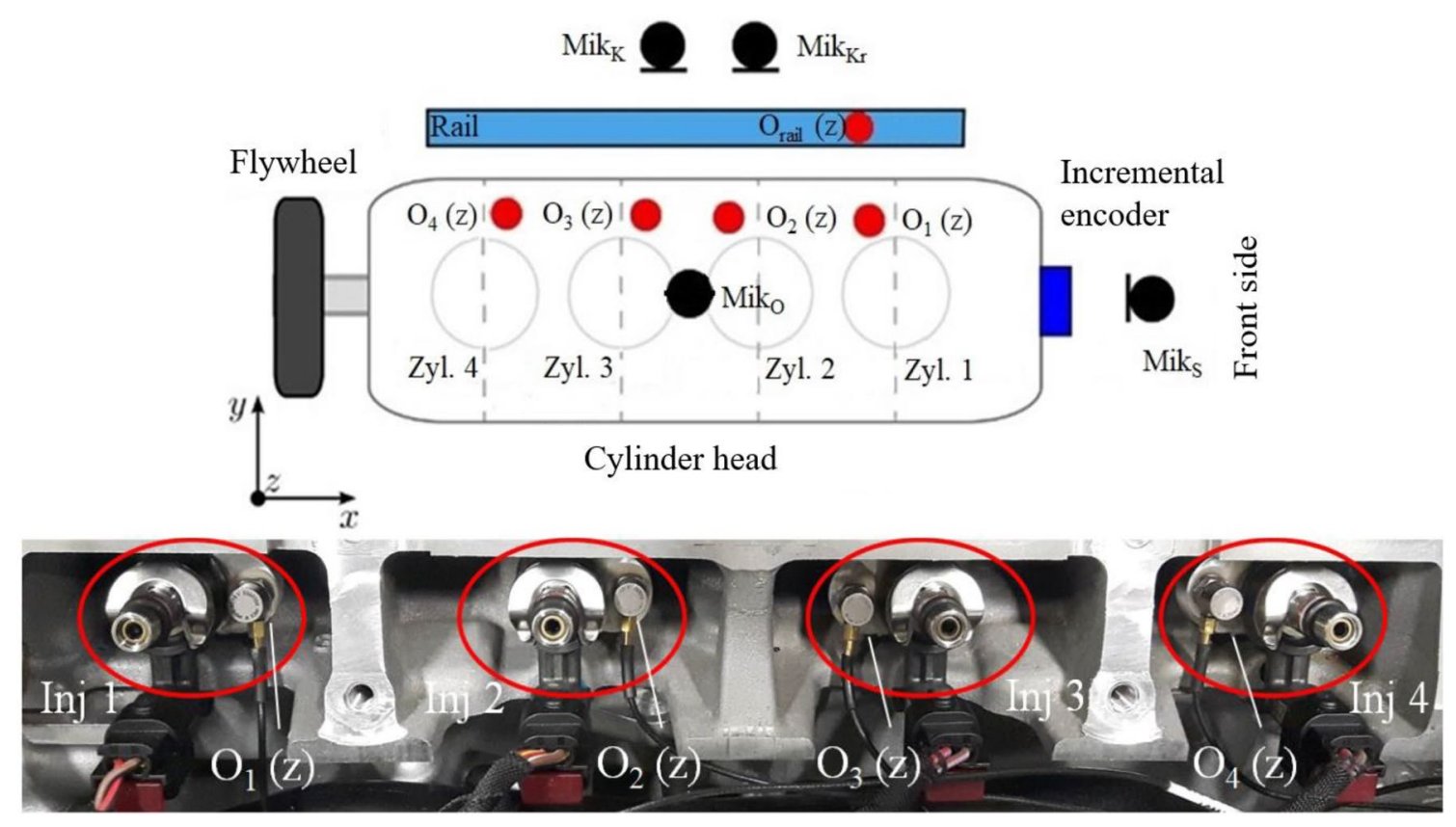

Fig. 6 Overview of the positioning of structure-borne noise sensors (red dots) and microphones on the gasoline engine 


\section{Psychoacoustic parameters}

Psychoacoustic parameters tend to be better for describing the quality of the noise and, above all, the comfort of the noise, considering factors, such as frequency of occurrence, intensity and frequency distribution. With regard to the topic presented in this thesis, the psychoacoustic parameters impulsiveness, loudness and sharpness play the most important roles.

\subsection{Loudness}

Die Loudness $N$ is defined as a psychoacoustic variable for evaluating loudness strength and is specified with the unit sone. Die Loudness $N=1$ sone corresponds to a $1 \mathrm{kHz}$ tone with a sound pressure level of $L_{\mathrm{p}}=40 \mathrm{~dB}$. The loudness is determined from the summation of the specific loudnesses $N_{\mathrm{S}}$

$N=\int_{z=0}^{24 \text { Bark }} N_{\mathrm{S}}(z) \mathrm{d} z$

on the division of 24 Bark groups in the hearing-specific frequency range. These frequency groups are frequency bands used by the human ear which, when lined up, form the tone scale with the unit Bark. The bandwidth of the Bark groups is non-linear and increases with increasing frequency. Since the loudness is a ratio scaling, a doubling of the loudness from 1 to 2 sone means a doubling of the perceived volume level. The loudness can be calculated with the aid of the volume level, which is a psychoacoustic comparative measure and can be read from the curves of equal loudness. The link between the loudness and the volume level $L_{\mathrm{N}}$ is given through

$L_{\mathrm{N}}=40+10 * \log _{2} \approx 40+33.3 * \lg N$

respectively

$\frac{L_{\mathrm{N}}-40}{10}=\log _{2} N$

with

$N=2^{0.1 *\left(L_{\mathrm{N}}-40\right)}$

\section{$[2,6,10]$.}

Each of the doubling of the loudness shown in Table 2 also corresponds to a doubling of the perceived volume level. In comparison, an increase in the volume level by 10 phon means a doubling of the perceived volume. This applies from a volume level of 40 phon. In numerous laboratory tests, it was found that the intensity of a sound event plays an essential role in the perception of loudness, but
Table 2 Relationship between loudness $\boldsymbol{N}$ and volume level $\boldsymbol{L}_{\boldsymbol{N}}$

\begin{tabular}{ll}
\hline $\begin{array}{l}\text { Lautheit } N \\
\text { [sone] }\end{array}$ & $\begin{array}{l}\text { Laut- } \\
\text { starkepegel } \\
L_{\mathrm{N}} \text { [phon] }\end{array}$ \\
\hline 32 & 90 \\
16 & 80 \\
8 & 70 \\
4 & 60 \\
2 & 50 \\
1 & 40 \\
$1 / 2$ & 32 \\
$1 / 4$ & 25 \\
$1 / 8$ & 19 \\
$1 / 16$ & 14 \\
\hline
\end{tabular}

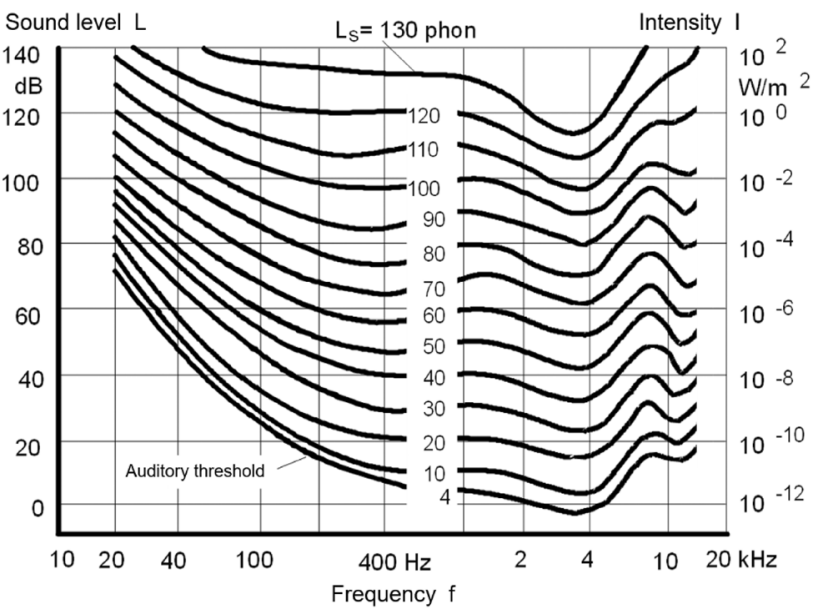

Fig. 7 Hearing field with curves of the same volume level $\boldsymbol{L}_{\boldsymbol{S}}$ for sine tones [11]

is not sufficient for determining loudness alone [10]. The influence of the frequency was shown using the curves of equal volume, see Fig. 7.

Since the human ear combines frequencies that are close together, so-called frequency groups are created. The influence of the spectral bandwidth only becomes significant for the loudness when the limits for a frequency group are exceeded. Thus, broadband noises at the same sound pressure level appear louder than narrowband noise events [10, 12]. Furthermore, temporal occlusions, such as pre- and post-occlusion, as well as spectral occlusion have an influence on the volume impression. In addition, the subjectively perceived volume is influenced by the duration of a noise. The longer the stimulus acts on the hearing, the higher the loudness. A final loudness is only reached after $200 \mathrm{~ms}$ [10]. Ultimately, the loudness gives a direct statement about how loud the person perceives the sound. However, no conclusion can be drawn from the 
pure loudness as to how pleasant or unpleasant a sound event is perceived.

\subsection{Impulsiveness}

The impulsiveness $I$ is a perception parameter that arises from rapid and large fluctuations in the sound level. It is mostly associated with the sound of diesel engines, but it also occurs in direct-injection gasoline engines. Although some test persons prefer an impulsive sound, for example a combustion engine noise, impulsive noises are often perceived as unpleasant [13]. The impulsiveness has the unit iu. Most approaches to determining the perceived impulsiveness are mostly based on the criteria.

- Number of impulses,

- Statistical distribution of the impulses per unit of time,

- Differences in level of the pulses per unit of time and

- Statistical distribution of the level differences between the impulses and the background noise

[1]. With regard to internal engine combustion and the resulting combustion noises, the impulsiveness plays a very important role in determining the extent of the diesel knocking or the ticking noise. For the computational investigation of such noises, different methods for determining the impulsiveness have emerged. The ratio between the peak value and the effective value of a signal level results in the so-called crest factor $c$, which describes the impulsiveness in a relatively simple way.

$c=\frac{L_{\max }}{L_{\text {eff }}}$

with $c$ is the Crest factor, $L_{\max }$ is the maximum level in $\mathrm{dB}$, $L_{\text {eff }}$ is the RMS value of the signal level in $\mathrm{dB}$.

Furthermore, the kurtosis $k$ can be used to describe the impulsiveness, which, however, only represents a measure of the steepness of an empirical frequency distribution [14]. This basically provides a better match than the crest factor, since the level difference to the background noise is taken into account. It consists of the signal amplitude change over time over a specified integration time.

$k=\frac{\frac{1}{N} \sum_{n=0}^{N-1} s(n)^{4}}{\left[\frac{1}{N} \sum_{n=0}^{N-1} s(n)^{2}\right]^{2}}$

with $k$ is the Kurtosis, $N$ is the number of samples, $s(n)$ is the signal value of the sample $n$

\subsection{Sharpness}

In contrast to the roughness, the sharpness $S$ is a suitable measure for the detection of noise components in the high-frequency range. Typical noises with a high degree of sharpness are, for example, hissing noises or the whistling of a turbocharger. The different calculation methods mostly represent the level ratio between low-frequency and high-frequency sound components. The unit acum is a linear mapping perception parameter. According to [15], narrowband noise at $1 \mathrm{kHz}$ and a sound pressure level of $60 \mathrm{~dB}$ are used as the reference sound and thus corresponds to 1 acum. The sharpness is a direct indicator of the tone color and thus has a strong influence on the sound euphony. The numerical value of the sharpness increases when the proportion of high frequencies in the amplitude spectrum increases. This can be done using the equation

$S=\frac{\int_{z=0 \text { Bark }}^{z=24 \text { Bark }} N^{\prime}(z) * g(z) * z * \mathrm{~d} z}{\int_{z=0 \text { Bark }}^{z=24 \text { Bark }} N^{\prime}(z) * \mathrm{~d} z}$ acum

with

$g(z)=1$ for $z \leq 15.8$ Bark

$g(z)=0.15 * e^{0.42(z-15.8)}+0.85$ for $z>15.8$ Bark

with $N^{\prime}$ is the specific loudness in sone/Bark, $z$ is the frequency group in Bark, $g(z)$ is the frequency group dependent weighting factor.

\section{Development of a formula for evaluating the ticker noise}

First, it is necessary to prove that it is possible to depict other engine noise phenomena, such as the ticker noise, by means of an empirical evaluation formula based on perception variables. For this purpose, the noise behavior of the individual injectors is first analyzed with regard to their opening and closing behavior in the frequency range to be able to differentiate them from the combustion noise. With the help of structure-borne noise signals, a direct comparison can be made on both test benches, since unlike the acoustic engine test bench, no meaningful airborne noise measurements are possible under free-field conditions on the injector test bench. It is then checked which psychoacoustic parameters are most suitable for evaluating the ticking noise components. 


\subsection{Frequency-based analysis of the injection behavior}

In the following, the injection processes based on the injection rate and the structure-borne noise signal, based on the stationary operation on the test engine and carried out on the injection analyzer, are evaluated in a special time-frequency analysis, the Smoothed pseudo Wigner-Ville distribution. The upper part of the figure shows the measured acceleration signal (gray line), its envelope (red line), the course of the injection rate (pink line), the control current (blue line) and the start (SOI: start of injection, dark gray), dashed) and ends (EOI: end of injection, black, dashed) of the injections. The actual Wigner-Ville distribution is shown in the lower area of the figures. The dashed, red area encompasses the area of the envelope of the structure-borne noise signal.

Figure 8 shows the Wigner-Ville distribution of an injection process, consisting of pre-injection and main injection. For this purpose, the parameters of the measurements on the engine test bench in stationary operation at a speed of $1750 \mathrm{rpm}$ and a load of $100 \mathrm{Nm}$ were adopted as follows:

- Rail pressure: $p_{\text {rail }}=865$ bar

- Injection duration of the pilot injection: $\Delta t_{\mathrm{PI}}=252 \mu \mathrm{s}$
- Injection duration of the main injection: $\Delta t_{\mathrm{MI}}=721 \mu \mathrm{s}$

- Distance $\mathrm{SOI}_{\mathrm{PI}}$ to $\mathrm{SOI}_{\mathrm{MI}}=16^{\circ} \mathrm{KW}$

As can be seen in Fig. 8, the highest amplitudes in the entire structure-borne noise signal are mostly to be found in the relatively low-frequency range, with the pre-injection area having a significantly higher energy level than the main injection area. This can be seen from the fact that in the area after $\mathrm{EOI}_{\mathrm{PI}}$, the highest levels extend over a larger time and frequency range. Furthermore, the reflections of the injection signals in the structure-borne noise can be detected as far as possible in this frequency range. This can also be seen in the envelope of the filtered raw signal of the acceleration sensor, in the upper part of Fig. 8, according to which the largest amplitudes (area of the pre-injection and main injection) in the time signal are followed by steadily decreasing amplitudes.

\subsection{Empirical ticker noise formula}

After the causes for the ticking behavior of the injectors in the frequency range have been found out, the empirical formula for determining the ticker noise component on the basis of perception-based variables is now to be developed.
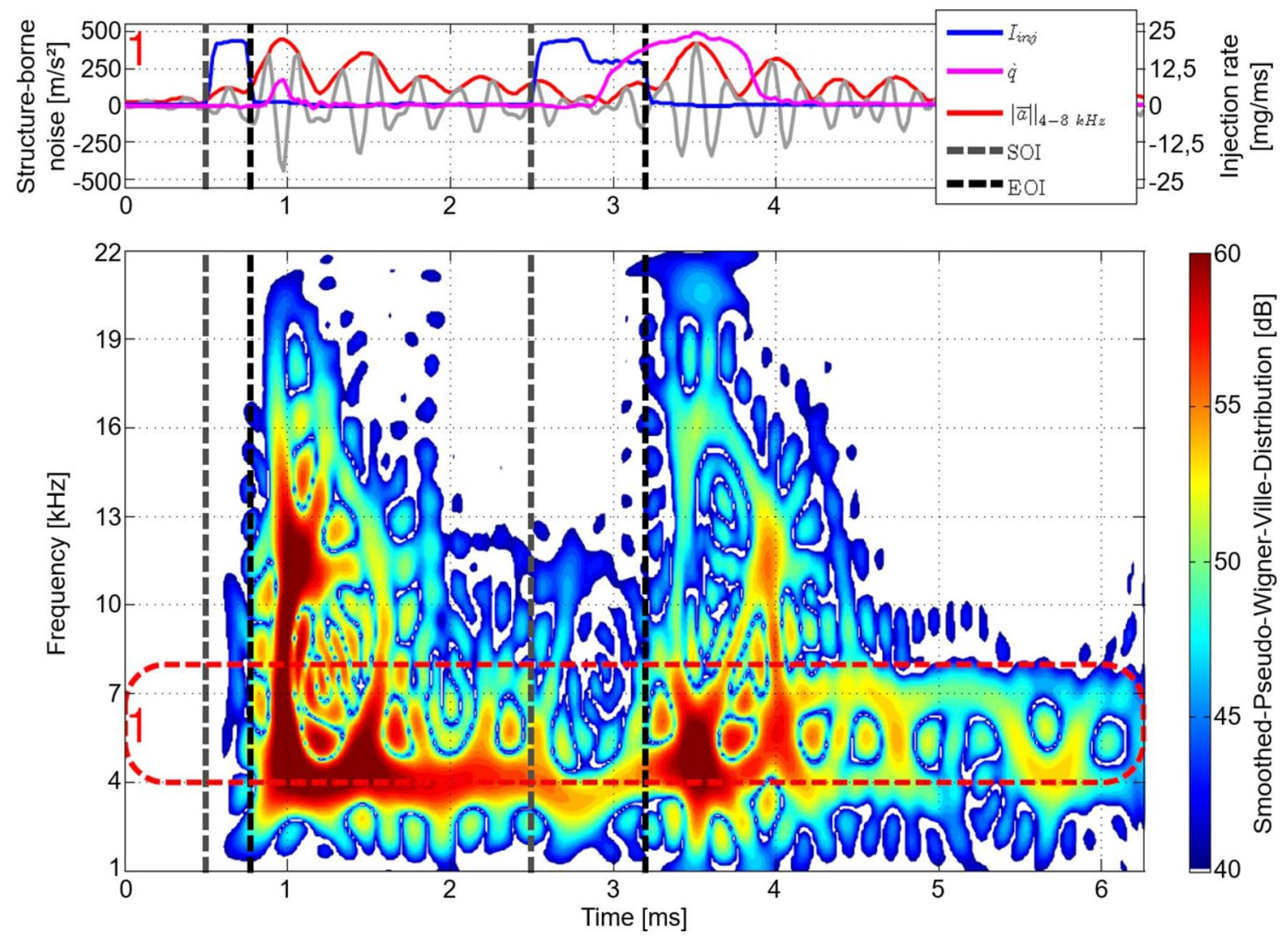

Fig. 8 Time-frequency analysis of the structure-borne noise signal of an injector, $f=4-8 \mathrm{kHz}$, unfired operation on the injector test bench 
Here, the psychoacoustic parameters are initially considered on their own. A ticking noise of the overall engine noise is perceived as very impulsive, but less loud than a knocking noise. Furthermore, unlike the knocking noise, the ticker noise is more likely to be assigned to the higher-frequency ranges.

\subsubsection{Loudness}

The perceived loudness of a gasoline engine increases relatively continuously with both engine speed and load in Fig. 9. The discrepancy between the influence of torque and speed is noticeable, with the loudness progression appearing discontinuously, especially at $1750 \mathrm{rpm}$ and $2250 \mathrm{rpm}$. Furthermore, the towed, no-load and part-load operating points of the gasoline engine were, as expected, rated as significantly less loud compared to the diesel engine, with the highest loudness ratings for both engines being almost the same. It is also noticeable that the mechanical noise in towing mode is less loud than when the engine is idling, regardless of the engine speed.

\subsubsection{Sharpness}

Furthermore, the evaluation of the sharpness is now considered in the following figures, whereby first the full engine operation and then the injector operation without the engine running will be discussed. Hereby, the rating based on Aures [16] is used.

It can be seen in Fig. 10 that the sharpness increases with the load, whereas the speed has a lower influence.

To be able to analyze the sharpness more specifically based on the ticking, investigations on the acoustic test bench without the engine running were aimed at, in which only the injectors but not the high-pressure pump could be operated, which is why it was not possible to build up pressure in the rail. Only the injection duration was adapted to the real engine operating points with regard to the speed, which can be seen in Fig. 11.

Regardless of this, a clear influence of the speed can be determined, since a higher-frequency injection pattern sounds sharper as a result. It can also be seen that in comparison to the sharpness distributions of the fired engine operation, significantly higher sharpness ratings were determined for pure injector operation, which supports the approach of the empirical ticker evaluation formula, according to which pure ticker noise is more sharp than rough noise due to its occurrence in the higher-frequency range. A connection between sharpness and impulsive noises has also already been demonstrated in [17].

A step-by-step increase in the injection duration without a corresponding rail pressure, on the other hand, hardly provides any information with regard to the evaluation of the sharpness. To be able to investigate the dependency of the rail pressure, the Injection Analyzer was used again, but without the possibility of using airborne noise signals. Rather, the structure-borne noise signals of the injection processes were considered when the rail pressure varied, with the sharpness ultimately being calculated. This can be seen in Fig. 12. Here, three operating points of different injection pressures were shown comparatively, with particularly large pressure differences being selected to obtain clear evidence of the dependency of the sharpness of a structure-borne noise signal with increasing rail pressure.

It can clearly be seen that, as expected, the amplitudes of the structure-borne noise signal increase with
Fig. 9 Loudness distribution of the torque-speed map

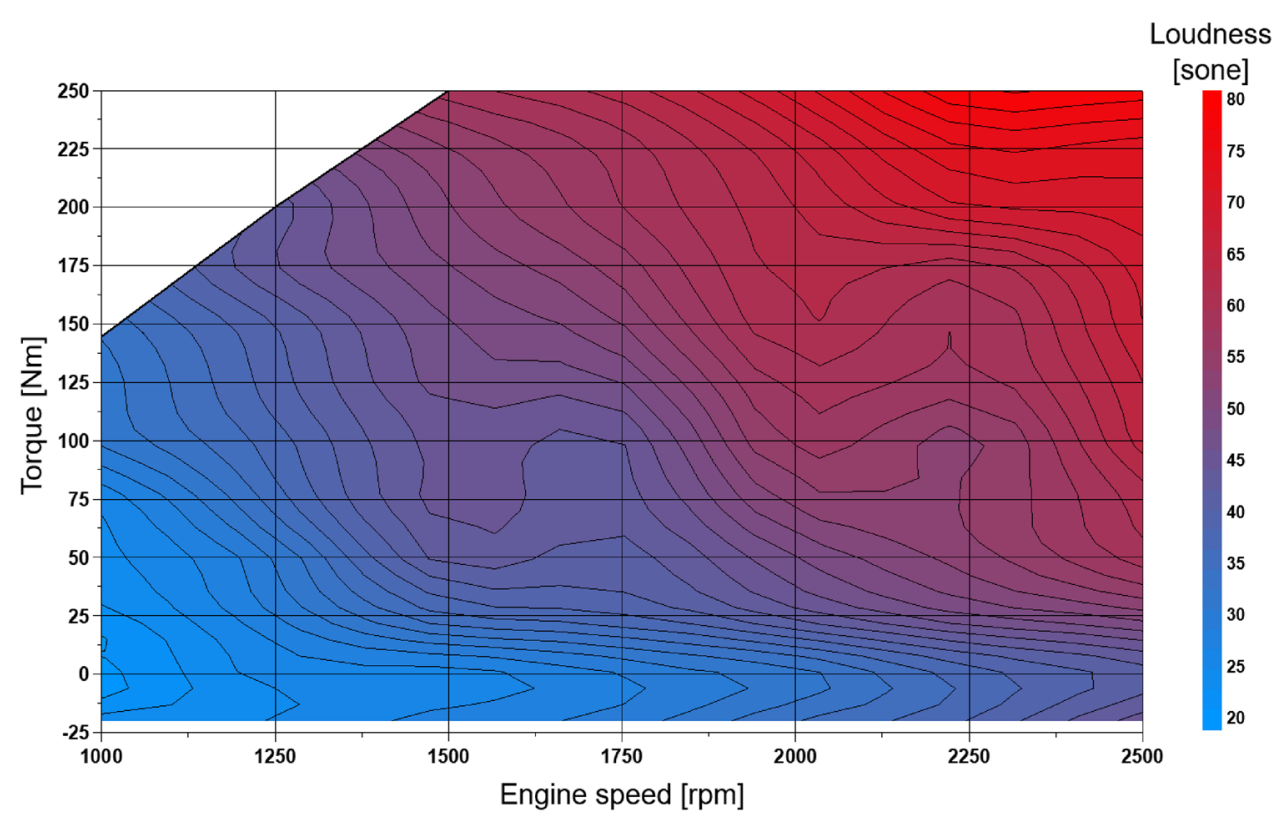


Fig. 10 Sharpness distribution of the torque-speed map
Sharpness

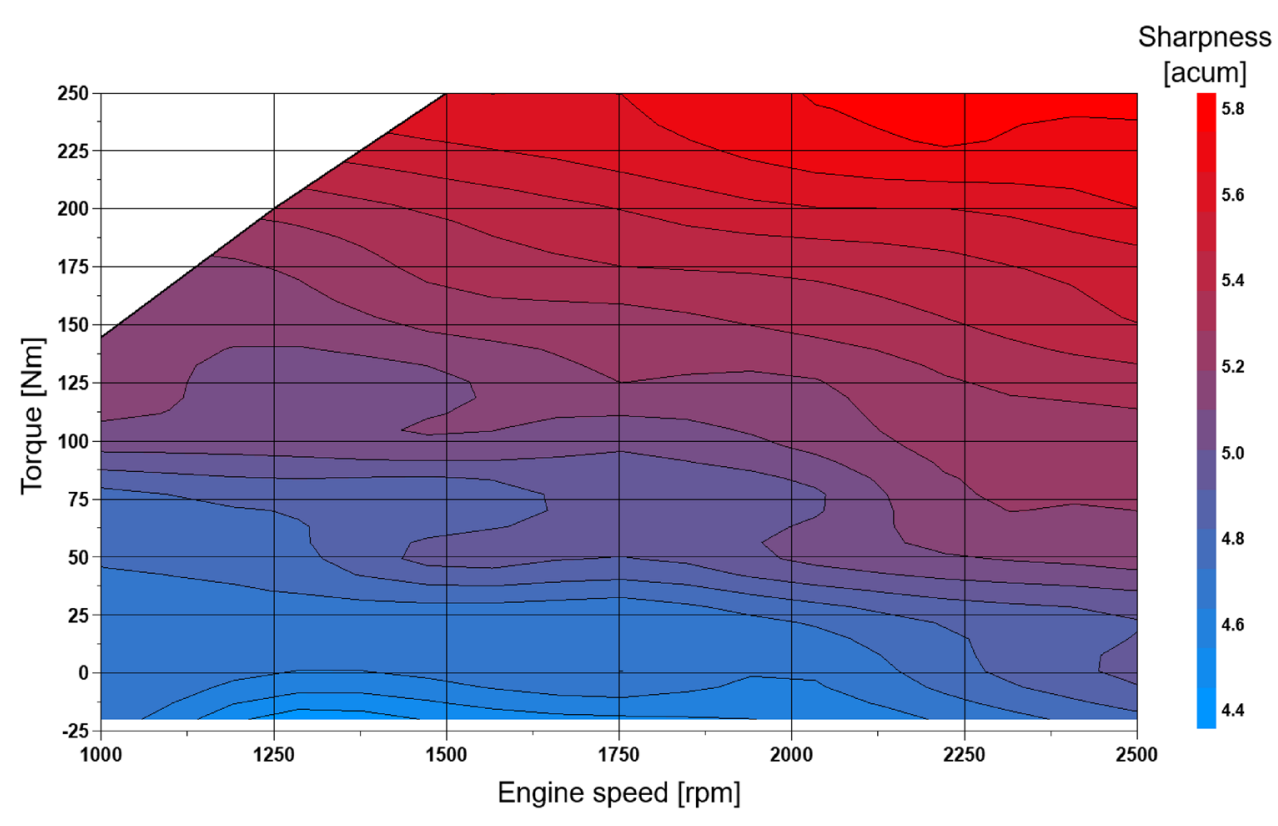

Sharpness

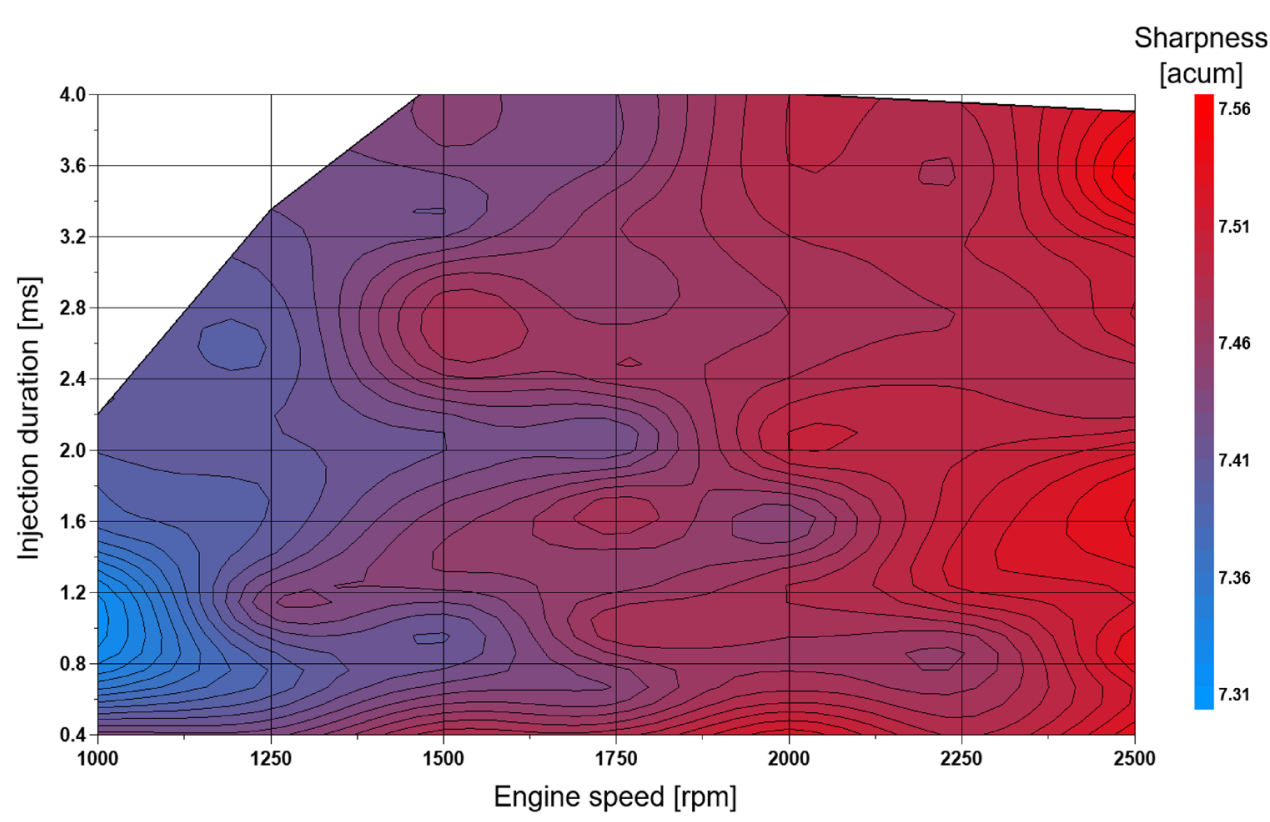

Fig. 11 Sharpness distribution of the injection duration/speed map for self-sufficient injectors without the engine running higher rail pressure. If the injection pressure is tripled (see center of the picture), the amplitudes almost double. If the pressure is increased fivefold (see picture on the right), the amplitudes increase almost threefold. If the sharpness assessment is now considered, it can first be established that acceleration signals of a ticking noise produce a higher sharpness than airborne sound signals. Furthermore, the sharpness increases rather degressively as the injection pressure increases linearly.

\subsubsection{Impulsiveness}

After considering the respective influence of loudness and sharpness with regard to the ticker noise components, the most important component of the ticker rating formula will now be discussed, the impulsiveness. The impulsiveness distribution of the gasoline engine map is shown in Fig. 13.

It can be seen that the highest impulsiveness values occur in the lower partial load range of the gasoline engine, the 


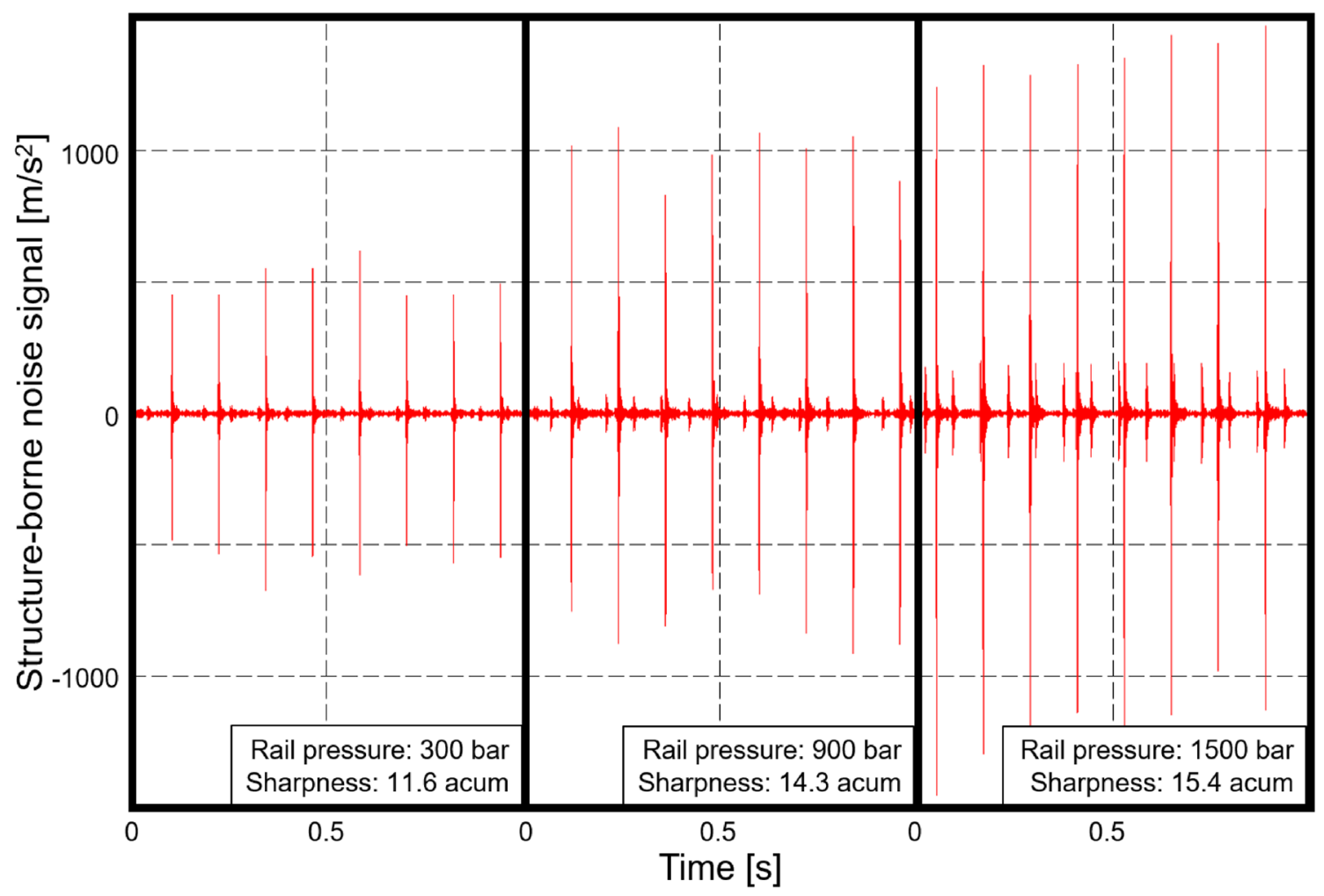

Fig. 12 Influence of the rail pressure on the sharpness evaluation of structure-borne noise signals

Fig. 13 Impulsiveness distribution of the torque-speed map
Impulsiveness

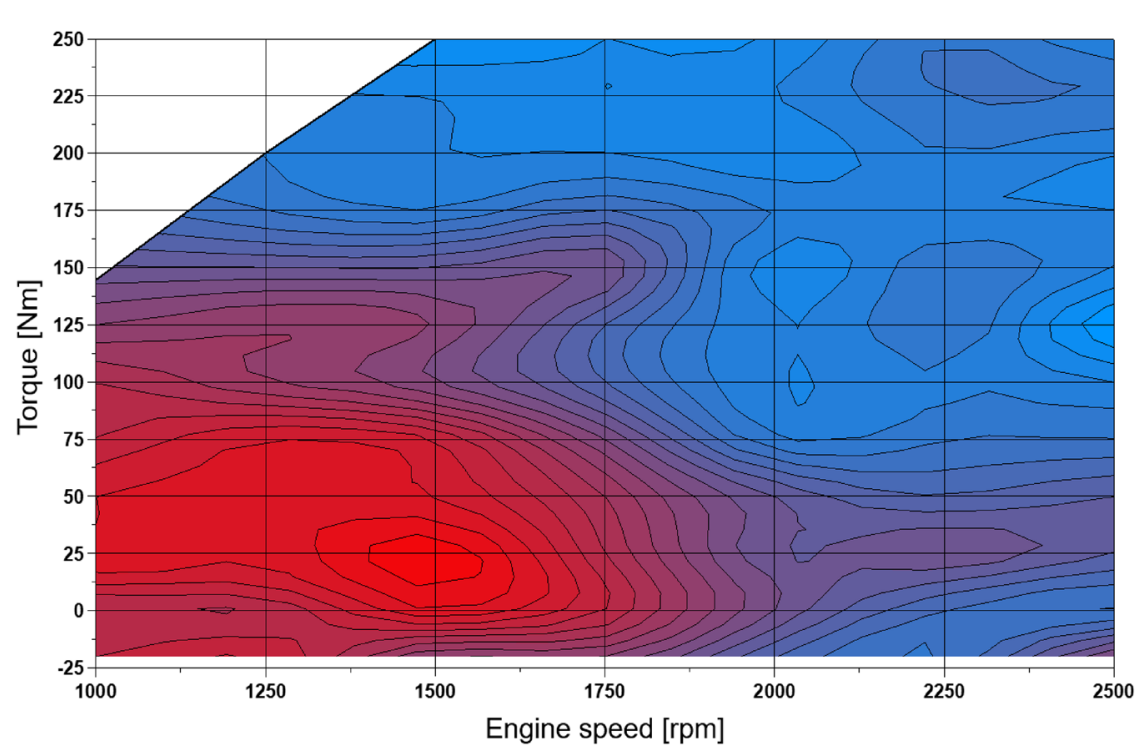

[iu] highest ratings being in a broader speed range at lower load. The load range of $25-50 \mathrm{Nm}$ is also noticeable. Not only can the most impulsive ratings be found there, the impulsive range also extends into the high-speed range.

After considering the individual psychoacoustic parameters, the empirical ticker noise evaluation formula will be developed with the aim of a uniform calculation method for gasoline engines. For this purpose, the diesel grade calculation formula from [18] is used as a basis, whereby the raw time data of the engine operating points to be evaluated are no longer calculated unfiltered, but are provided with a high-pass filter at $2 \mathrm{kHz}$ to exclude the lower-frequency 
combustion noise influences as far as possible in advance. The empirical formula is first iteratively developed further through the subjective perception of an individual, to then be validated and thus objectified through hearing tests. So, the basis of the ticker grade is the following formula:

$\mathrm{TN}=a * S+b * I+c * N+d$

For the ticker grade, it is essential to define grade limits to fix grades 1 and 10 so that all engine operating points to be examined are mathematically within this scale range. For this purpose, the evaluation of the most impulsive injector operating point without the engine running was determined as grade 1 by varying the parameters of the formula. For the upper limit, an engine operating point with towed operation, and thus without operation of the injectors, and a very high speed was selected. Figure 14 shows the ticker grade limits.

After defining the limits and taking the results of the individual psychoacoustic variables into account, the formula parameters are defined, so that the following formula is ultimately created:

$\mathrm{TN}=-(a * S * 0.4997+b * I * 0.26894+c * N * 0.154)+13.4$

\subsection{Hearing tests to evaluate the ticker noise}

The ticker grade must now be validated by hearing tests to be able to serve as an objective tool of evaluating noises. For this purpose, the tests were carried out in the hearing cabin

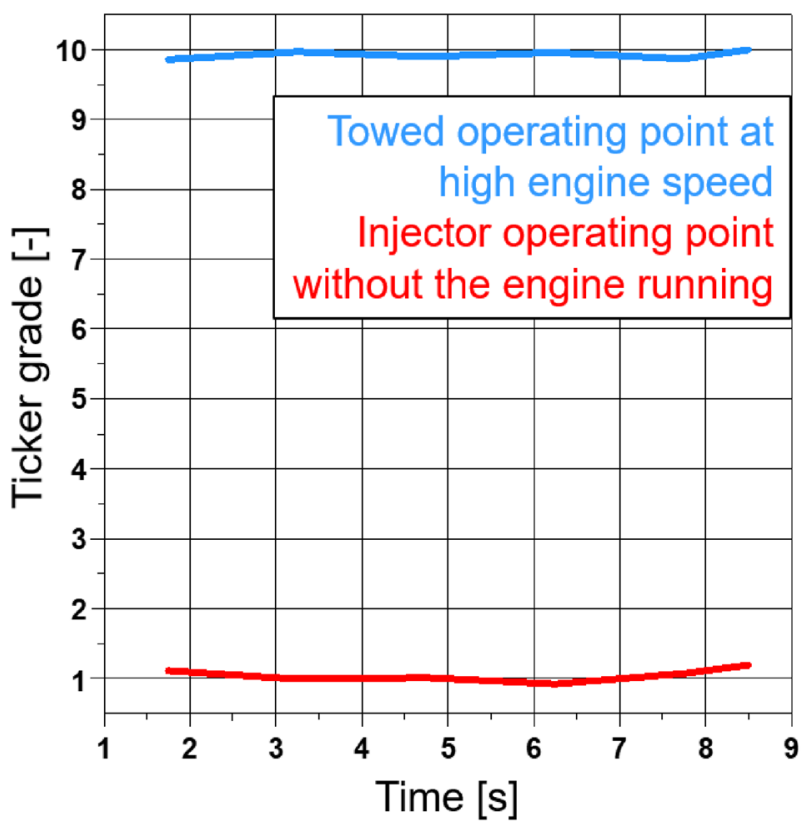

Fig. 14 Ticker grade comparison of a towed operating point at high speed with a maximum ticking injector operating point without the engine running of the Otto-von-Guericke-University of Magdeburg. A total of 75 selected stationary gasoline engine noise signals highpass-filtered at $2 \mathrm{kHz}$ in the ranges from 1000 to $1750 \mathrm{rpm}$ as well as from towed to full load operation with a length of $3 \mathrm{~s}$ were examined by means of a categorical evaluation, in which the 15 tested subjects, which were classified as experts, used a scale from 1 to 10 to rate the perceived ticker noise. In addition, introductory noises were used to be able to give the test subjects a feeling before the actual hearing test as to the extent to which a strongly ticking engine noise differs from a slightly ticking engine noise.

When comparing the hearing tests with the empirical formula based on the gasoline engine noises, a clearer result was expected in advance than with a diesel engine due to the lower effects of combustion noise. This comparison can be seen in Fig. 15. The speed range from 1250 to $1750 \mathrm{rpm}$ at $25-50 \mathrm{Nm}$ is particularly noticeable, since both grade distributions show their global maxima there. As expected, the towed and high load ranges show lower ratings, with slight deviations being seen in the middle load range.

In summary, the statement can be made that the empirical formula for evaluating the ticker noise generally achieves good results, which concludes the validation of the ticker grade.

\section{Summary}

As part of this article, a psychoacoustic evaluation method for the noise of the gasoline engine was developed. The aim here was to pursue a purely sensation-based approach to evaluate the internal combustion engine noise to be able to bring the subjectivity of human perception more to the fore. For this purpose, the differences between the background noises on the gasoline engine were examined more closely with regard to the relevant psychoacoustic parameters, whereupon the original evaluation approaches for the ticker noise were examined. This gave rise to the opposing idea of only using psychoacoustic parameters and largely fading out the physical acoustics. For this purpose, the individual psychoacoustic variables with regard to the examined engine unit were considered in a wide range of characteristics. Ultimately, a preselection was made as to which perceptionbased variables would be suitable for the formula approach. The choice fell on the impulsiveness, the loudness and the sharpness. For this purpose, the Injection Analyzer was first used for the ticker noise analysis, with which the individual noise components in the injector could be determined both in the time and in the frequency domain. The Smoothed pseudo Wigner-Ville distribution proved to be an effective tool for analyzing the separate noise phenomena during the injection and combustion processes. This made it possible to detect the ticker noise as precisely as possible in airborne 


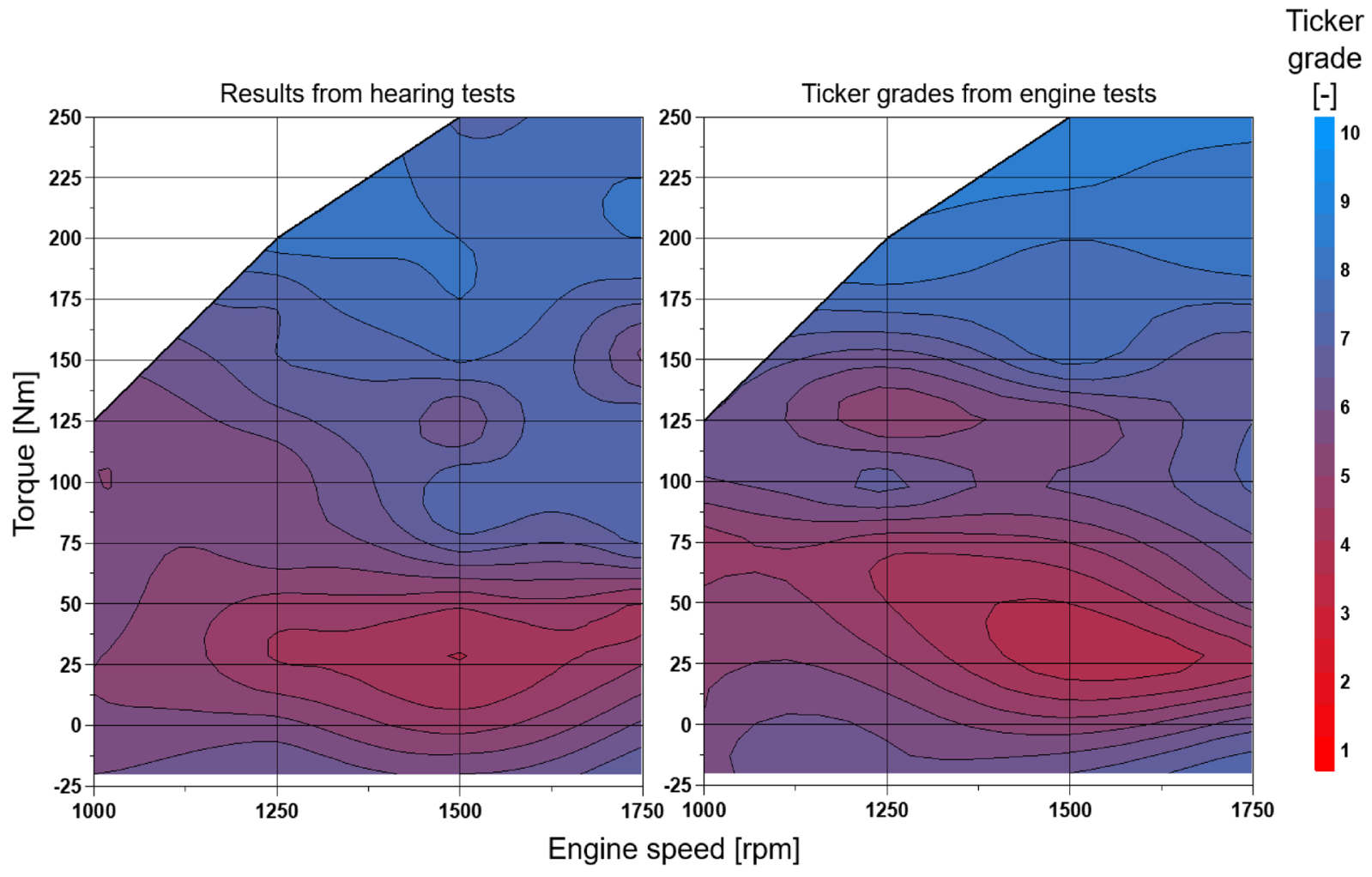

Fig. 15 Comparison of the hearing test results with the ticker rating distribution of the gasoline engine map

and structure-borne noise. Based on this, the psychoacoustic variables were combined in an empirical formula with experimentally determined weighting coefficients, which were iteratively adjusted. After completion of the formula, it was validated with the help of hearing tests with a sufficiently good correlation between the empirical formula and the subjective perception of the test subjects.

Funding Open Access funding enabled and organized by Projekt DEAL.

Open Access This article is licensed under a Creative Commons Attribution 4.0 International License, which permits use, sharing, adaptation, distribution and reproduction in any medium or format, as long as you give appropriate credit to the original author(s) and the source, provide a link to the Creative Commons licence, and indicate if changes were made. The images or other third party material in this article are included in the article's Creative Commons licence, unless indicated otherwise in a credit line to the material. If material is not included in the article's Creative Commons licence and your intended use is not permitted by statutory regulation or exceeds the permitted use, you will need to obtain permission directly from the copyright holder. To view a copy of this licence, visit http://creativecommons.org/licenses/by/4.0/.

\section{References}

1. Pflüger, M., Brandl, F., Bernhard, U., Feitzelmayer, K.: Fahrzeugakusti. Springer-Verlag, Wien (2010)

2. Zeller, P.: Handbuch Fahrzeugakustik. Vieweg+Teubner-Verlag, Wiesbaden (2012)

3. Atzler, M.: Bewertungsmodelle für impulsartige Störgeräusche von Verbrennungsmotoren, Dissertation, Aachen (2011)

4. Mühlbauer, C., Rabl, H.-P., Rottengruber, H.: Development of a methodology for acoustic analysis and optimization of mechatronic fuel injection systems. In: Springer Fachmedien Wiesbaden, Ruschlikon, Schweiz, Automotive Acoustics Conference (2019)

5. Schumann, C., Pischinger, S.: Zerlegung von Motorgeräuschen in einzeln anhörbare Komponenten, deren objektive Bewertung sowie Zuordnung zu den geräuschverursachenden Bauteilen bzw. Prozessen, FVV (2017)

6. Möser, M.: Psychoakustische Messtechnik. Springer Vieweg Verlag, Wiesbaden (2018)

7. Mühlbauer, C., Rabl, H.-P., Rottengruber, H.: Akustische Analyse und Optimierung von Mechatronischen Kraftstoffeinspritzsystemen. DAGA, Rostock (2019)

8. Atzler, M., Pischinger, S.: Erarbeitung objektiver Kennwerte zur Bewertung der Lästigkeit verschiedener impulshaltiger Geräuscharten von Verbrennungsmotoren auf Basis subjektiver Beurteilungen, FVV (2010)

9. Schneider, S., Carstens, J.H., Nobis, J., Joerres, M., Rottengruber, H., Gühmann, C.: Körperschallbasierte Dieselmotorenregelung-Optimierung und Adaption der Parameter, FVV (2016) 
10. Genuit, K.: Sound-Engineering im Automobilbereich - Methoden zur Messung und Auswertung von Geräuschen und Schwingungen. Springer-Verlag, Berlin (2010)

11. Fastl, H., Zwicker, E.: Psychoacoustics-Facts and Models. Springer-Verlag, Berlin (2007)

12. Sinambari, G.R., Sentpali, S.: Ingenieurakustik: Physikalische Grundlagen und Anwendungsbeispiele. Springer-Verlag, Wiesbaden (2014)

13. Willemsen, A. M., Rao, M.D.: Characterization of sound quality of impulsive sounds using loudness based metric. In: 20th International Congress on Acoustics, Sydney, Australia (2010)

14. Rönz, B., Strohe, H.G.: Lexikon Statistik. Gabler Verlag, Wiesbaden (1994)

15. Messtechnische Simulation der Hörempfindung Schärfe, DIN 45692:2009-08, Frankfurt am Main (2009)
16. Aures, W.: Der Wohlklang: Eine Funktion der Schärfe, Rauhigkeit und Klanghaftigkeit. DAGA, Darmstadt (1984)

17. Hoechstetter, M., Sautter, J.M., Gabbert, U., Verhey, J.L.: Role of the duration of sharpness in the perceived quality of impulsive vehicle sounds. Acta Acustica United Acustica, Frankfurt am Main (2016)

18. Hoppermanns, J., Pischinger, S., Lange, B.: Erarbeitung objektiver Kennwerte zur Bewertung der Lästigkeit verschiedener Geräuscharten von Verbrennungsmotoren auf Basis subjektiver Beurteilungen, FVV (2006)

Publisher's Note Springer Nature remains neutral with regard to jurisdictional claims in published maps and institutional affiliations. 